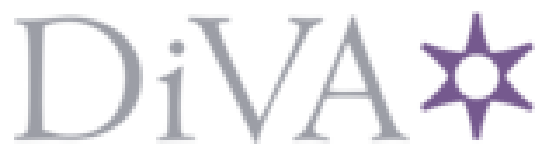

http://www.diva-portal.org

This is the published version of a paper published in Nordic journal of nursing research.

Citation for the original published paper (version of record):

Paillard-Borg, S., Kraft, M. (2021)

Becoming a global nurse: A thematic and interpretive analysis of bachelor's theses at the Swedish Red Cross University College

Nordic journal of nursing research

https://doi.org/10.1177/20571585211050331

Access to the published version may require subscription.

N.B. When citing this work, cite the original published paper.

Permanent link to this version:

http://urn.kb.se/resolve?urn=urn:nbn:se:rkh:diva-4126 


\title{
Becoming a global nurse: A thematic and interpretive analysis of bachelor's theses at the Swedish Red Cross University College
}

Nordic Journal of Nursing Research

(SSAGE

\author{
Stéphanie Paillard Borg (iD) and Mia Kraft (iD
}

\begin{abstract}
The overall purpose of this study was to initiate the process of developing a comprehensive theoretical framework associating the three entities defining the Swedish Red Cross University College (SRCUC): global nursing, global health and Red Cross and Red Crescent's perspective (RCRC). To do so, an analysis of nursing bachelor's theses over two periods (201 I-20I2 and 20I52016) was initially needed to capture the academic essence. Two specific aims were defined: I) To describe how global nursing and global health, in conjunction with the RCRC perspective, were addressed and contextualized in nursing bachelor's theses; and 2) To investigate how students' knowledge in global awareness and vision has developed over time. Two overarching themes were identified: Conceptualizing caring relations and moving towards the body of global awareness and Understanding the art of nursing and ethics in complex nursing actions. The Standards for Reporting Qualitative Research (SRQR) guidelines were used to ensure the trustworthiness of the findings. By promoting relevant knowledge, the SRCUC prepares future nurses for upcoming health needs at the planetary level.
\end{abstract}

\section{Keywords}

global health, humanitarian work, nursing values, Red Cross and Red Crescent Movement

Accepted: 15 September 2021

\section{Background}

The International Council of Nurses (ICN) has three primary functions: to represent nursing worldwide, to advance the profession, and to influence health policy. ${ }^{1}$ However, nursing seems to have difficulties in finding its place and identity on the global scene as it is underrepresented in the key global health organizations, whereas nurse-led organizations are comparatively weak and lacking in influence. ${ }^{2}$ Sadly, the lack of a unified global nursing influence has been connected to the relatively low visibility from low-income countries, indigenous peoples, and other disadvantaged groups. Recently, there has even been worldwide criticism of the fact that the mass media have underplayed the role and voice of nurses to the advantage of expert opinions under the COVID-19 pandemic. $^{3}$

Nursing actions are tailored traditionally to suit the challenges related to human vulnerability. ${ }^{4-6}$ These last years, nursing educators have put a strong emphasis on sustainable nursing and health inequities. ${ }^{7-15}$ The effort nowadays around the world is to educate global nurses. ${ }^{14}$ Consequently, some universities and nursing schools have developed a strategic remodelling of their educational vision and curriculum, stressing the importance of sustainability and globality., $911,16-24$ Professional identities and socialization into practical skills are central to nursing education, but self-efficacy in different care environments is also of major importance. ${ }^{25,26}$ On these lines, the Swedish Red Cross University College (SRCUC) is continuously developing its unique profile and has adopted a dynamic approach to the growth of the nursing profession locally and globally within the context of global health. ${ }^{27}$

At the SRCUC, established in 1867, various educational activities rest on the principles of the Red Cross and Red Crescent (RCRC) Movement. ${ }^{27}$ The SRCUC has a long tradition of global networking consistent with the movement's humanitarian profile, and RCRC nurses are specially trained to alleviate suffering, safeguard human dignity and to become activists to support vulnerable people. ${ }^{27-30}$ It was not until the year 2000, after a national review of the undergraduate nursing programme, that it was uncovered that the global nursing profile area fostered by the SRCUC was unsatisfactory, as described by Holmgren and Kraft. ${ }^{31}$ Consequently, the global nursing profile needed to be, first, developed further and, second, implemented throughout the undergraduate nursing programme in a systematic manner. ${ }^{27,31}$ Figure 1 displays the final and official definition of global nursing at the SRCUC.

Department of Health Sciences, The Swedish Red Cross University College, Huddinge, Sweden

\section{Corresponding author:}

Stéphanie Paillard Borg, The Swedish Red Cross University College, Department of Health Sciences, SE-I4I 21 Huddinge, Sweden.

Email: pais@rkh.se 


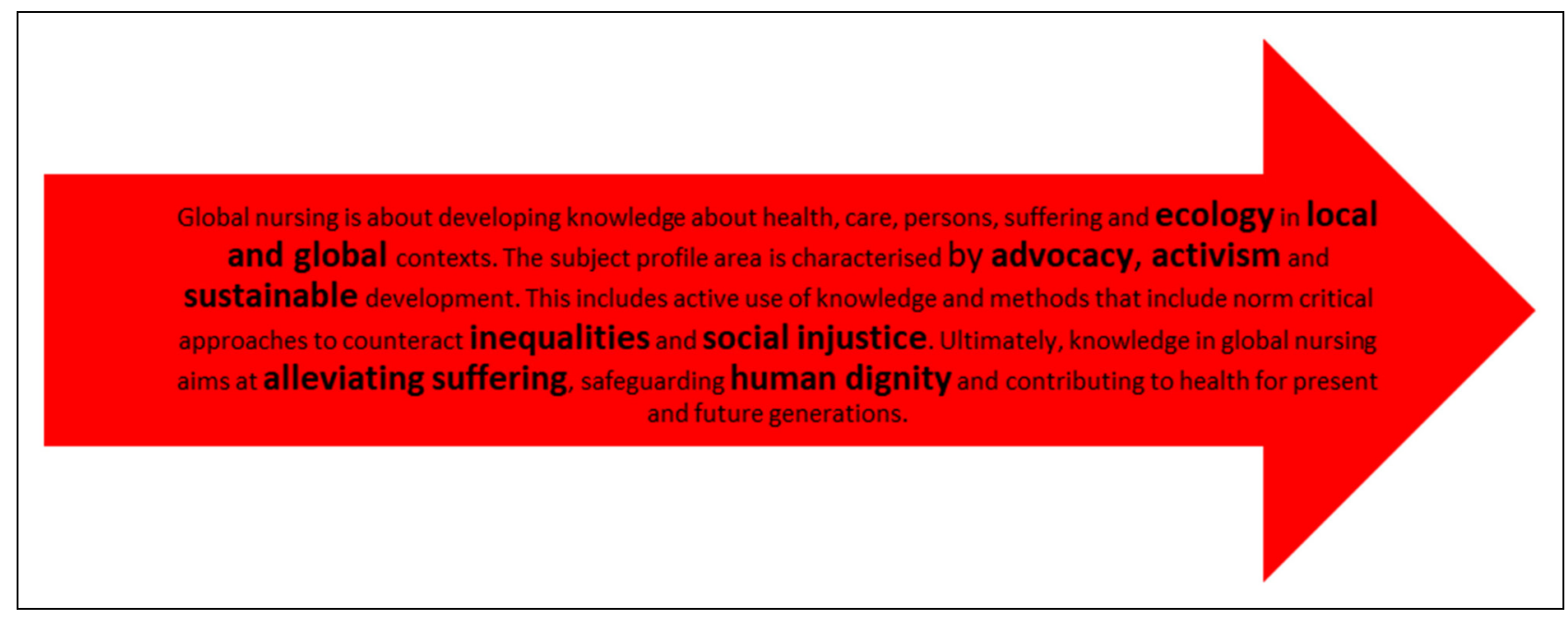

Figure I. The Swedish Red Cross University College profile area definition by Holmgren. ${ }^{27(p .127)}$

In the year 2017, once the global nursing definition was finally and officially endorsed by the SRCUC, it was adequate to also revise a global health definition corresponding to the newly defined profile. The definition was inspired by prominent research groups in the field of global health. ${ }^{30,32,33}$ Its description was based on previous publications and embodied both globality and health. The global health profile, in line with the RCRC Movement's humanitarian perspective, was constructed on the precept of its international approach to health issues that transcend geographical boundaries as well as its multidisciplinary and interdisciplinary perspectives combining both public health and nursing aspects. The following text is the official definition of global health at the SRCUC:

Global health is an interdisciplinary field for a wide range of evidence-based practice and research that addresses the health issues that have the potential to transcend national, state and geographical boundaries. The primary goal of global health is equality in and improvement of the health of people, groups, and populations worldwide. Global health is defined by multidisciplinary and interdisciplinary approaches and methods in which health is considered in the perspective of the individual, the community and the environment. ${ }^{34}$

Also, the 17 Sustainable Development Goals (SDGs) for 2016-2030 play an important role in defining global health as an action framework to achieve, the ultimate global health challenge being the global eradication of poverty. ${ }^{35}$ The goals are intricately interconnected, and they offer a central global structure for health policy and practice. The World Health Organization (WHO) leads the effort to support the development of the SDGs. ${ }^{36}$

In 2017, the International Federation of Red Cross and Red Crescent Societies (IFRC) presented a report describing a baseline of thematic issues based on Strategy 2030 and identified ten thematic futures focusing on populations' vulnerabilities (Figure 2). ${ }^{37}$

A common characteristic in global nursing, global health and RCRC activities is reactivity. This mutual trait needs continuous updates and revisions to reflect the global situation. In parallel, there is an urgency to educate future nurses who will be able to show flexibility and preparedness in facing planetary challenges. Therefore, based on the complexity and multifaceted aspect of the SRCUC academic profile, the overall purpose of this study was to initiate the process of developing a comprehensive theoretical framework associating the three entities defining the SRCUC: global nursing, global health and RCRC perspective. An analysis of nursing bachelor's theses over two periods (2011-2012 and 2015-2016) was needed to capture the academic essence and significance of these three entities. The first aim was to describe how global nursing and global health, in conjunction with the RCRC perspective, were addressed and contextualized in nursing bachelor's theses. The second was to investigate how students' knowledge in global awareness and vision had developed over time. This study targets all health professionals with an operational and academic interest in global nursing and global health with a focus on humanitarian actions supported by organizations such as the RCRC Movement.

\section{Method}

This descriptive study with a thematic and interpretive design was implemented to answer the overall purpose and the two aims of this study. This design offers the potential to catch the way people interpret and make perceptions of everyday practices. ${ }^{38,39}$ The Standards for Reporting Qualitative Research (SRQR) guidelines were used to ensure that all relevant and expected information were presented when appropriate (Appendix 1 in the supplemental material online). ${ }^{40}$

\section{Context}

At the SRCUC, about 900 students are studying in a first- or second-cycle programme. The undergraduate nursing programme leads to a bachelor's degree in nursing science and a professional degree in nursing. The programme comprises 180 ECTS (European Credit Transfer and Accumulation System) credits in total, based on full-time studies. The division of the ECTS credits are as follows: nursing science 102 ECTS 


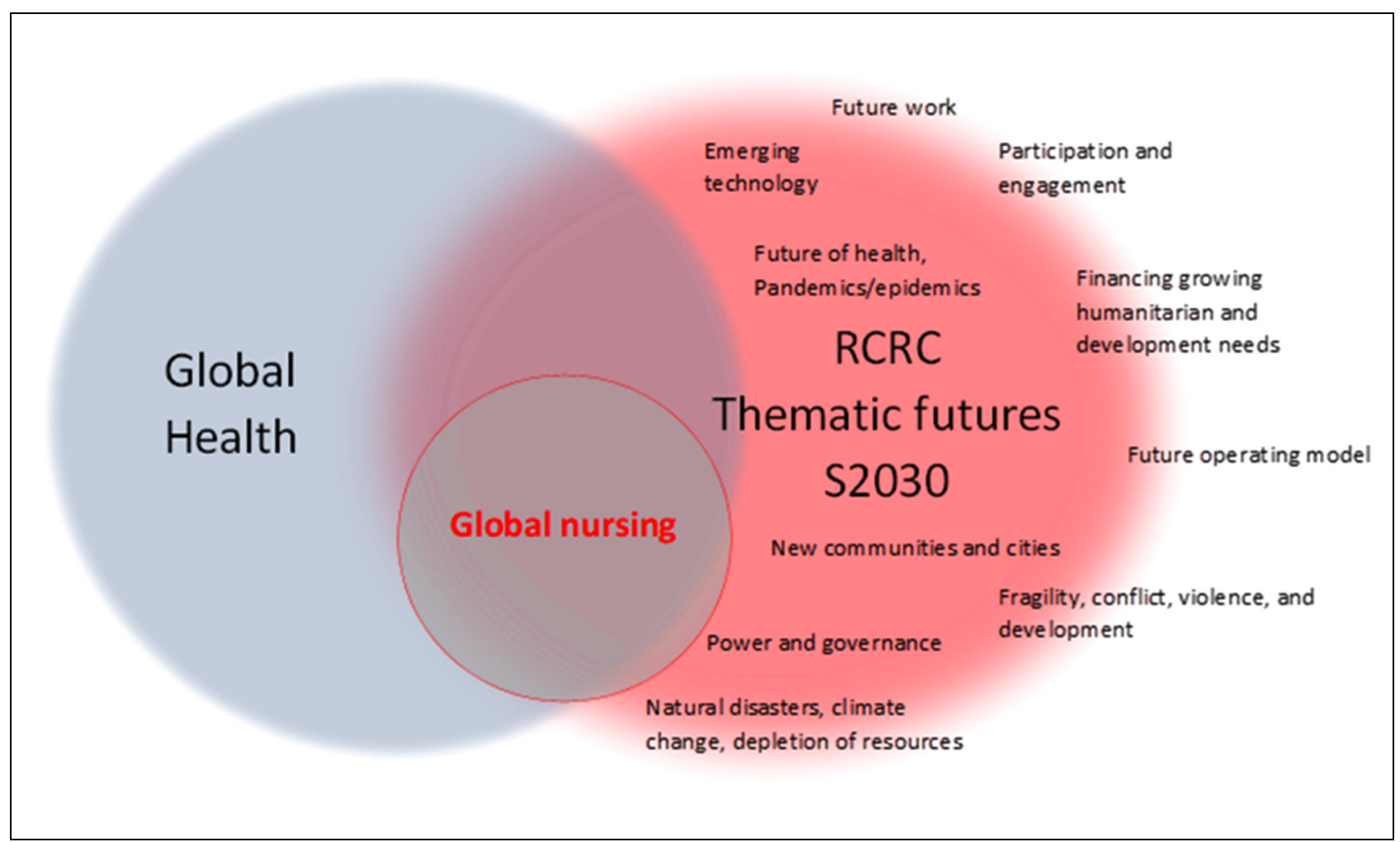

Figure 2. Global health, global nursing, and Red Cross and Red Crescent Thematic Futures S2030.

credits; medicine, 48 ECTS credits and public health sciences 30 ECTS credits. Most of the courses are designed to incorporate all three subject areas. The bachelor's thesis is conducted during the last year of the programme.

\section{Data collection}

The literature search was purposive to scrutinize SRCUC students' bachelor's theses. A professional librarian with knowledge of the guidelines for publication in the Digitala Vetenskapliga Arkivet (DiVA) portal was consulted in January 2021 before initiating the search process. The portal is a finding tool and an institutional repository for research publications and theses produced at 49 universities and research institutions in Sweden. The two authors (MK and SPB) together with the librarian initiated the first literature search for the 18-month period, January 2011 to June 2012. This was done to increase the validity of the search. The search terms combined in single literature searches for each semester were as follows: bachelor's thesis, spring semester 2011, autumn semester 2011, spring semester 2012, and the Swedish Red Cross University College. The selection of this first period was intentional for two reasons. The first is that DiVA had become operational at the SRCUC only from 2011. The other reason is that this time frame coincides with the happening of major events, involving global health, that had a potential impact on the students' nursing perspective. During the years 2011-2012, the beginning of the war in Syria, the humanitarian consequences of the 'Arab spring', the tsunami in Japan and the Fukushima disaster were among the mediatized events that shocked the world. In the second literature search, another 18-month period was selected including: bachelor's thesis, spring semester 2015, autumn semester 2015, spring semester 2016. The choice of this subsequent period was also deliberate, as during this time the 'migration crisis' took over political concerns in Sweden. Issues pertaining to racism, human rights and right to healthcare, unemployment, nationalism versus patriotism were exacerbated by the media. ${ }^{41}$ In addition, an intensification of terror attacks took place around the world during 2015-2016. During these events, healthcare workers and the RCRC Movement had a central role and were largely mediatized. ${ }^{42}$ Another motivation for opting for this second period is that we wished to have a significant time gap between the two periods to avoid an overlap.

A total of 114 bachelor's theses with 74 literature studies and 40 interview studies were included in the study. Each thesis included between 20 and 30 pages and was written in English or Swedish. At the time of this study, the two authors were employed as lecturer (MK) and senior lecturer (SPB) at the university college, but they did not have any previous contact with the students whose theses were included in this study.

\section{Data analysis}

The empirical material of the bachelor's theses was analysed by using thematic and interpretive data synthesis by Evans, in several stages. ${ }^{38,39}$ A deductive approach ${ }^{43}$ was adopted to structure the students' texts according to the SRCUC profile area definitions for global nursing ${ }^{27}$ and global health, ${ }^{30,32,33}$ with SDGs as a framework in the first reading and the RCRC Thematic Futures S2030 ten thematic focus areas in the second reading (Table 1). ${ }^{35,37}$ As thematic analysis is an 
Table I. An example of the analysis within theme 'Global fragility in the local context'.

\begin{tabular}{|c|c|c|c|c|}
\hline $\begin{array}{l}\text { Data material consisted of } \\
\text { four (4) interview studies } \\
\text { (IS) and six (6) literature } \\
\text { studies (LS) }\end{array}$ & $\begin{array}{l}\text { First reading: core concepts of } \\
\text { the SRCUC global health and } \\
\text { global nursing definitions, and } \\
\text { the SDGs }\end{array}$ & $\begin{array}{l}\text { Second reading: RCRC } \\
\text { Thematic Futures S2030 } \\
\text { ten thematic focus areas }\end{array}$ & Sub-themes & Theme \\
\hline $\begin{array}{l}\text { Contexts: Homelessness/visiting } \\
\text { hostels (IIS), undocumented } \\
\text { immigrants/assessing health } \\
\text { and human rights (2LS), } \\
\text { threats and violence in close } \\
\text { relationships (IIS, 3LS), Child } \\
\text { abuse (IIS), Tanzania } \\
\text { hand-hygiene (IIS) FGM in } \\
\text { world (ILS). } \\
\text { Patients: children, homeless } \\
\text { persons, undocumented } \\
\text { immigrants, asylum seekers, } \\
\text { women suffering from } \\
\text { violence and threats, women/ } \\
\text { girls suffering from rape and } \\
\text { sexual violence. } \\
\text { Profession: caring relations, } \\
\text { encountering vulnerability } \\
\text { and suffering, showing } \\
\text { accountability in encounters } \\
\text { with undocumented persons, } \\
\text { sustainable caring, } \\
\text { encountering asylum seekers, } \\
\text { encountering women/girls } \\
\text { victims/survivors of rape and } \\
\text { sexual violence, } \\
\text { human-to-human } \\
\text { relationship, suffering/hope, } \\
\text { hierarchical care actions. }\end{array}$ & $\begin{array}{l}\text { Accountability Activism Advocacy } \\
\text { Asylum seekers Caring relations } \\
\text { Child abuse Eliminate violence } \\
\text { against women and girls SDG } \\
\text { 5.2.I Healthcare-associated } \\
\text { infections/basic hygiene Health } \\
\text { work force SDG 3.c Human } \\
\text { rights ICN future nurses Person } \\
\text { Power relations in nursing } \\
\text { Mobilization of resources SDG } \\
\text { I.I Non-communicable diseases } \\
\text { SDG 3.4 Sexual and reproductive } \\
\text { health SDG 3.7 Suffering } \\
\text { Sustainability Undocumented } \\
\text { migrants Universal health } \\
\text { coverage SDG 3.8 Vulnerability } \\
\text { Violence SDG I6.I }\end{array}$ & $\begin{array}{l}\text { Thematic Future } \\
\text { nr. 5. Participation and } \\
\text { engagement - Here comes } \\
\text { everybody Thematic Future } \\
\text { nr. 2. Fragility, conflict, } \\
\text { violence, and development } \\
\text { Example of discussion notes/ } \\
\text { reflexive journaling after } \\
\text { completion of first and second } \\
\text { reading: The students have } \\
\text { discussed how to develop } \\
\text { nurse engagement, social } \\
\text { awareness, and accountability } \\
\text { in caring relations within } \\
\text { healthcare contexts in } \\
\text { conflicting situations where } \\
\text { people are suffering. How to } \\
\text { identify and manage social } \\
\text { suffering, fragility, and } \\
\text { marginalization in health. To } \\
\text { take into action local } \\
\text { challenges of global character. } \\
\text { The mobilization of resources } \\
\text { is essential. Nurses must be } \\
\text { aware of local problems that } \\
\text { are also global. The students } \\
\text { discover that the world's } \\
\text { problems are coming into their } \\
\text { world and the notion of 'we } \\
\text { and them' is fading away. }\end{array}$ & $\begin{array}{l}\text { Understanding the } \\
\text { notion of 'we and } \\
\text { them' } \\
\text { Vulnerabilities in local } \\
\text { contexts } \\
\text { Management of social } \\
\text { suffering, fragility, } \\
\text { and marginalization } \\
\text { in local contexts }\end{array}$ & $\begin{array}{l}\text { Global } \\
\text { fragility } \\
\text { in the } \\
\text { local } \\
\text { context }\end{array}$ \\
\hline
\end{tabular}

Note. SRCUC: the Swedish Red Cross University College; SDG: Sustainable Development Goal; RCRC: Red Cross and Red Crescent; FGM; female genital mutilation; ICN: International Council of Nurses.

iterative and reflective process, the analysis was developed over time and engaged a constant moving back and forth between the stages. ${ }^{38,43}$ Also, this deductive analysis was driven by the authors' theoretical interest and might give a more complete analysis of some aspects of the data but tends to produce a less rich explanation of the overall data. ${ }^{43}$

The empiric material from the 114 theses was repeatedly and inductively read by each author individually searching for meanings and patterns and to gain a sense of the texts as a whole. ${ }^{38,43}$ Then, the texts were organized in a file within two groups: years 2011-2012 and 2015-2016. After separate reading, face-to-face meetings between the authors took place and discussions started about how to proceed with the deductive theming of the data and how to provide a rich and detailed documentation for the analysis process and report. ${ }^{43,44}$ Discussions were set down in writing using reflexive journaling. ${ }^{45}$ These include values, interests, and growing insights about the research topic and keeping track of what the data mean. ${ }^{45,46}$ The reading progressed with retrieving key findings from each thesis. A coding matrix was developed to structure and to reduce the texts to the key findings (Table 2). ${ }^{45}$ The attention was on details of accounts, the underlying meanings in each thesis, and the patterns in which the different texts depicted the core concepts of the SRCUC definitions and the SDGs. During this reading, the theses' IMRaD (Introduction, Methods, Results, and Discussion) organizational structure helped the authors to find relevant data and, in the texts, the title, abstract, theoretical concerns, and results section were carefully examined. Likewise, patient groups involved in different caring contexts or caring approaches were detected. During this stage, the authors also made notes about ideas for analysis of details that could be returned to subsequent phases. ${ }^{45}$ If disagreements between the two authors occurred in this reading, a separate and individual analysis was repeated. Then, the key findings were further discussed and checked. ${ }^{38}$

The listed key findings were further read repeatedly, separately, and discussed by the two authors to gain an understanding of how they could apply to the RCRC Thematic Futures S2030 ten thematic focus areas. ${ }^{38}$ After this, key findings were revised, and the thematic and interpreted analysis went on to identify common themes by grouping a set of meanings related to ontological and epistemological assumptions that support the research construction. Every theme was to capture a distinctive element in relation to the overall research question. $^{43}$ From there, differences between themes were 
Table 2. A coding matrix to identify key findings.

\begin{tabular}{|c|c|c|c|c|c|}
\hline Thesis number/year & $\begin{array}{l}\text { Title/ } \\
\text { abstract }\end{array}$ & $\begin{array}{l}\text { Theoretical } \\
\text { considerations }\end{array}$ & Results & & \\
\hline $\begin{array}{l}\text { Framework in the first reading } \\
\text { SRCUC Global nursing definition with core concepts } \\
\text { SRCUC global health definition with core concepts } \\
\text { I7 SDGs } \\
\text { GOAL I: No Poverty } \\
\text { GOAL 2: Zero Hunger } \\
\text { GOAL 3: Good Health and Well-being } \\
\text { GOAL 4: Quality Education } \\
\text { GOAL 5: Gender Equality } \\
\text { GOAL 6: Clean Water and Sanitation } \\
\text { GOAL 7: Affordable and Clean Energy } \\
\text { GOAL 8: Decent Work and Economic Growth } \\
\text { GOAL 9: Industry, Innovation, and Infrastructure } \\
\text { GOAL 10: Reduced Inequality } \\
\text { GOAL I : Sustainable Cities and Communities } \\
\text { GOAL 12: Responsible Consumption and Production } \\
\text { GOAL 13: Climate Action } \\
\text { GOAL I4: Life Below Water } \\
\text { GOAL 15: Life on Land } \\
\text { GOAL 16: Peace and Justice Strong Institutions } \\
\text { GOAL I7: Partnerships to achieve the Goal }\end{array}$ & Yes/no & Yes/no & Yes/no & $\begin{array}{l}\text { Framework in the second reading } \\
\text { The RCRC Thematic Futures S2030 } \\
\text { ten thematic focus areas } \\
\text { I. Natural Disasters, Climate } \\
\text { Change, and Depletion of } \\
\text { Resources } \\
\text { 2. Fragility, conflict, violence } \\
\text { and development } \\
\text { 3. Power and Governance } \\
\text { 4. New Communities and Cities } \\
\text { 5. Participation and engagement - } \\
\text { 'Here comes everybody' } \\
\text { 6. Emerging Technology 7. Financing } \\
\text { Growing Humanitarian and } \\
\text { Development Needs } \\
\text { 8. Future of Work } \\
\text { 9. Future of Health, Pandemics/ } \\
\text { Epidemics } \\
\text { 10. Future Operating Model }\end{array}$ & Yes/no \\
\hline
\end{tabular}

Note. SRCUC: the Swedish Red Cross University College; RCRC: Red Cross and Red Crescent.

compared, likewise, categorized into areas of similarity. ${ }^{45}$ Analysis went on to collate and formulate interpreted themes and overarching themes with their broader meanings and implications. $^{38}$ Sub-themes were identified from the interpreted themes and the thematic analysis continued by re-examining the sub-themes related to the overall aims and the interpreted themes. All sub-themes were described with extracts of raw data to illustrate the complex story of the data. ${ }^{43}$

Finally, consistencies and incongruities were re-assessed. In addition, the overarching themes were re-examined and discussed by the authors in relation to the organizing framework (Figure 3). ${ }^{38}$ The SRQR guidelines safeguarded the trustworthiness of the findings through the whole analytical process. ${ }^{40}$

\section{Ethical considerations}

According to the Swedish Ethical Review Act ${ }^{47}$ no ethical approval was required for this study. The DiVA database is an 'open access' tool, and its main purpose is to disseminate research and other publications openly available to the outside world and therefore no authorization from the authors of the bachelor's theses was necessary. All data were conducted confidentially and were only available to the authors. Data were stored on a laptop with a password that was not connected to the Internet during the analysis process.

\section{Findings}

Two overarching themes were identified: Conceptualizing caring relations and moving towards the body of global awareness and Understanding the art of nursing and ethics in complex nursing actions (Table 3 ). The corresponding overarching themes are supported by five themes and 12 subthemes in the period 2011-2012, and four themes and nine sub-themes in 2015-2016.

\section{Advocating participation in caring relations}

These future nurses showed an interest in the mutual caring interplay between nurses and patients. The importance of understanding the quality of the encounter is recurrent. Also, gaining deeper knowledge about interactions with patients and their loved ones is crucial to the students. In addition, adaptability to various caring contexts to improve the needs of the patients was frequently noted. Students commented on the complexity of caring relations as thus:

The result revealed a complex picture of attitudes and treatment of patients with obesity ... Health professionals should meet the patient from the patient's context and make their own context invisible. For that obesity should not be taboo nurse should focus on talking to the patient and to focus on the patient's experience rather than the diagnosis. In this way the patient's need will be satisfied and patient will feel confidence of the nurse. (nr. 7, spring 2011)

Another thesis emphasized the importance of communication in encountering families:

The result showed that parents wanted to be involved in their child's care and valued when nurses asked personal 


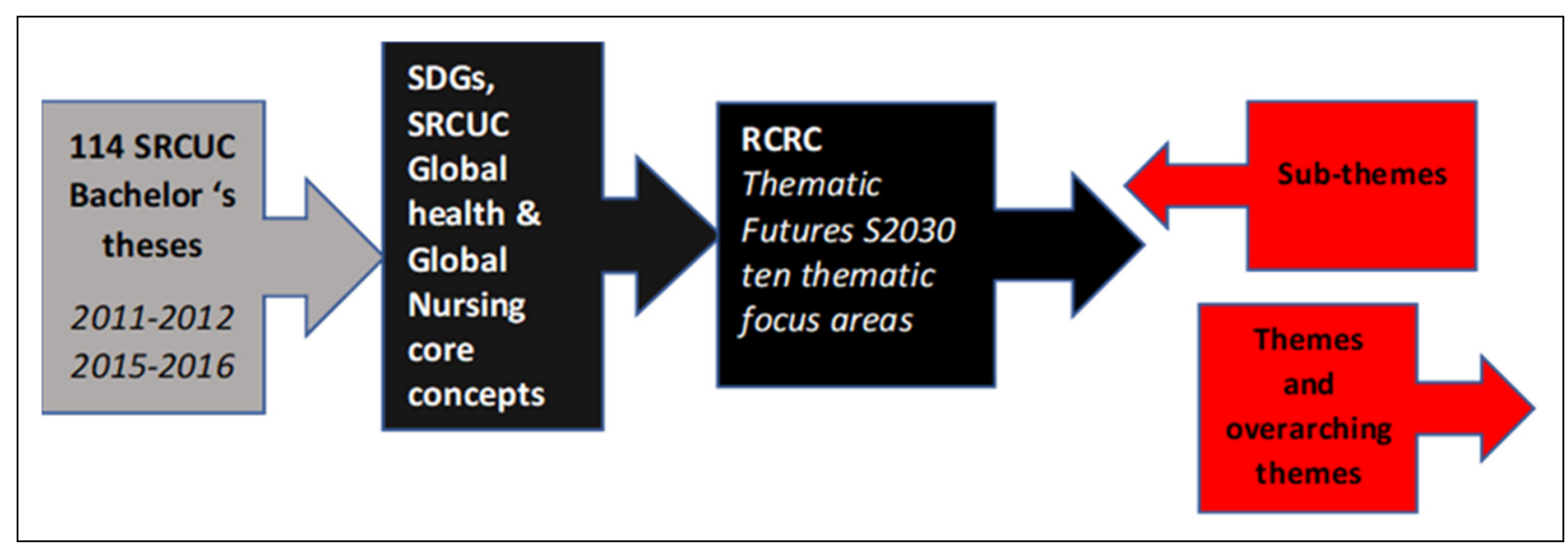

Figure 3. Analysis.

Table 3. Overarching themes, themes, and sub-themes.

20I I-2012 Overarching theme Conceptualizing caring relations and moving towards the body of global awareness

\begin{tabular}{|c|c|c|c|}
\hline Themes & Sub-themes & Themes & Sub-themes \\
\hline $\begin{array}{l}\text { Advocating participation in } \\
\text { caring relations }\end{array}$ & $\begin{array}{l}\text {-Active engagement of both nurses and } \\
\text { patients } \\
\text {-Future nurses' voice in caring relations } \\
\text { through multiple contexts }\end{array}$ & $\begin{array}{l}\text { Integrating sustainability and } \\
\text { advocacy with holistic } \\
\text { nursing }\end{array}$ & $\begin{array}{l}\text {-Integration of sustainability in } \\
\text { complex caring contexts } \\
\text {-Advocating for specialist nursing } \\
\text { and a holistic perspective }\end{array}$ \\
\hline $\begin{array}{l}\text { The global transition of } \\
\text { activism and professional } \\
\text { development }\end{array}$ & $\begin{array}{l}\text {-Transitions in global professionalism } \\
\text {-Awareness about global changes in } \\
\text { nursing care } \\
\text { - Expansion of global competencies by } \\
\text { professional and geographical } \\
\text { networking }\end{array}$ & $\begin{array}{l}\text { Commitment to vulnerable } \\
\text { populations with mental } \\
\text { illnesses }\end{array}$ & $\begin{array}{l}\text {-Future nurses' resilience in } \\
\text { caring for patients with mental } \\
\text { illnesses } \\
\text {-Nursing actions in social } \\
\text { vulnerabilities related to mental } \\
\text { illnesses }\end{array}$ \\
\hline $\begin{array}{l}\text { Global fragility in the local } \\
\text { context }\end{array}$ & $\begin{array}{l}\text {-Understanding the notion of 'we and } \\
\text { them' } \\
\text {-Vulnerabilities in local contexts } \\
\text {-Management of social suffering, fragility, } \\
\text { and marginalization in local contexts }\end{array}$ & $\begin{array}{l}\text { The meaning of ethical } \\
\text { principles }\end{array}$ & $\begin{array}{l}\text {-Awareness about a need for } \\
\text { specialist nurses and ethical } \\
\text { values } \\
\text {-Nursing actions guiding active } \\
\text { listening, empathy, and respect } \\
\text {-Interest in legal questions, law, } \\
\text { and guidelines }\end{array}$ \\
\hline $\begin{array}{l}\text { Ecology of nursing in global } \\
\text { health contexts }\end{array}$ & $\begin{array}{l}\text {-Mobilization of future nurses in activism, } \\
\text { green nursing, and ecology } \\
\text {-Sustainable balance between } \\
\text { environment and patients } \\
\text {-Non-pharmaceutical therapies }\end{array}$ & $\begin{array}{l}\text { Challenges in nursing actions } \\
\text { for a complex future }\end{array}$ & $\begin{array}{l}\text {-Disaster nursing in focus } \\
\text {-Stepping away from traditional } \\
\text { nursing approaches }\end{array}$ \\
\hline $\begin{array}{l}\text { Humanitarian aspects of } \\
\text { advocacy and activism }\end{array}$ & $\begin{array}{l}\text {-Humanitarian nursing actions involve } \\
\text { past, present and future problems/ } \\
\text { solutions. }\end{array}$ & & \\
\hline
\end{tabular}
2015-2016 Overarching theme Understanding the art of nursing and ethics in complex nursing actions

\section{The global transition of activism and professional development}

As global awareness is increasing, future nurses must understand that networking beyond borders is necessary in developing their global competencies and the transition into global professionalism. Consciousness about the complexity of different cultural contexts was expressed as the following:

Moreover, the multiple clinical nursing settings awakened the curiosity of the future nursing students as they understand that their future profession will require flexibility.
In many cases, misunderstandings, incomprehension, stereotyping, and discrimination form the basis for the suffering. 
This shows that the cultural safety needs to be improved in the healthcare system and that there is a need for increased cultural competence. (nr. 10, spring 2012)

In conjunction with the global health perspective, the students' Red Cross activities intensified their understanding of the various humanitarian interventions around the world.

\section{Global fragility in the local context}

The deep understanding and the consequences of the concept of 'we and them' in a nursing context has become central for the students. A paradigm shift appeared as they discovered that global health issues considered previously as 'exotic' had also become prevalent in their immediate surroundings. The conclusion of a thesis was conveyed with these words:

To increase knowledge about female genital mutilation, education of students and existing health-care professionals is required. (...) Consequently, the identification and management of social suffering, fragility, and marginalization was made in the local context. (nr. 12, spring 2012)

At this point, students have become aware of health matters, such post-traumatic stress disorder (PTSD) caused by conflicts or female genital mutilation (FGM) as belonging as well to the burden of disease of high-income countries.

\section{Ecology of nursing in global health contexts}

Concepts such as 'ecology', 'maintaining healthy environments' and 'green nursing' or 'non-pharmaceutical treatment' became increasingly of interest to students. These future nurses understand that the health of the population is dependent on its environment and that they play a key role in this situation. A student used the example of tactile massage to illustrate this approach:

This literature review show that tactile massage is seen mostly welcomed by patients and their relatives, regardless of diagnosis, care, or accommodation form. Tactile massage is an easy way to increase wellbeing and to confirm the bond between patient and care giver. More research is necessary on specific patient groups to increase comprehension and to strengthen the evidence based on the knowledge on tactile massage as a nursing intervention. (nr. 8, autumn 2011)

The role of ecology in relation to health can take different forms, and non-pharmaceutical approaches such as tactile massage are among these alternatives as they respect a sustainable ecosystem.

\section{Humanitarian aspects of advocacy and activism}

Some nursing students showed a strong interest in humanitarian nursing actions and especially the ones who wrote empirical studies gathering data in low- and middle-income countries, mainly in Ghana and Tanzania. The content of their theses presented factors related to poor health, such as stigmatization, poverty and unsustainable health systems. An example of nursing action is stated here:

The findings show a need for broadening the knowledge about mental illness in the Ghanaian community; nurses could help eradicating the stigmatization of mentally ill persons. (nr. 5, spring 2012)

The structural framework of the RCRC principles at the SRCUC has accentuated the humanitarian role of future nurses.

\section{Integrating sustainability and advocacy with holistic nursing}

The interests of these future nurses appeared complex, and they were receptive to the integration of diverse health perspectives within various caring contexts. The concept of sustainability together with 'marginal' therapies such as dog therapy or spiritual nursing are described as thus:

Spiritual care considered be a part of holistic care of health professionals but experience difficulties to apply in practice by the diffuse definition. Spiritual care should be related to the patient's well-being and not medical diagnoses. (nr. 1, spring 2016)

This approach showed congruence with the role of advocate that students are gradually integrating into their professional identity as future nurses. Reflections beyond traditional nursing and less conventional solutions in caring contexts are investigated.

\section{Commitment to vulnerable populations with mental illnesses}

Mental illness was thought by the students to be a highly prevalent problem in a variety of caring settings. Future nurses understand that mental illness is often a contributing factor to ill health. This understanding of increased complexity in caring competencies is expressed as follows:

There is a lack of studies that investigate how to encounter patients suffering from PTSD and healthcare personnel. Patients risk unnecessary suffering when the meeting with healthcare personnel fails. (nr. 3, spring 2015)

The intricate link between mental illness and social vulnerabilities was highlighted cleverly in several theses where the RCRC basic principles and the global health perspective were adequately brought to the discourse.

\section{The meaning of ethical principles}

In parallel to the complexity in nursing actions globally, the importance of ethical awareness appeared to expand exponentially. As interest in specialist nursing is expanding, attention on ethical and moral dilemmas grows. An example including ethical issues was: 
The nurse's participation in the caring team about the stance of maintaining or sustaining life support care is inadequate. The study also highlights the nurses' need for increased knowledge of laws, guidelines, and ethics. (nr. 2, spring 2016)

Closely related to ethical questions, the attention to legal matters, guidelines and laws in general have become increasingly described in the theses. The future nurses understand the importance of the legal aspect of the profession.

\section{Challenges in nursing actions for a complex future}

The students displayed a clear interest in disaster and military nursing closely related to humanitarian actions. A student expressed the responsibility of nursing in a disaster situation as follows:

\begin{abstract}
The nurse is expected to guide, direct, and coordinate the working team while he/she himself will perform his/her own duties as a nurse while being responsible for the safety of others and their care. The environment in which these nurses work is challenging but have during recent years become even more so due to natural and manmade disasters. (nr. 20, spring 2015)
\end{abstract}

This interest in nursing has become prevalent as a new normalcy within undergraduate nursing.

\section{Discussion}

This study had two specific aims. The first was to describe how global nursing and global health, in conjunction with the RCRC perspective, were addressed and contextualized in nursing bachelor's theses, and the second was to investigate how students' knowledge in global awareness and vision had developed over time. The two distinct overarching themes, Conceptualizing caring relations and moving towards the body of global awareness and Understanding the art of nursing and ethics in complex nursing actions, reveal the process of strengthening the multifaceted global vision of the nursing profession at the SRCUC over a relatively short but intense period. The development of a process is the combination of multiple events that interplay with each other. ${ }^{48}$ As such, the overarching themes reflect the academic background of the SRCUC as well as the overall global and national context around the time of the writing of the theses. Hübinette and Lundström provided a description of the Swedish contextual complexity in relation to globalism and migration under this period. ${ }^{4,50}$ Their findings depict racial marginalization in Sweden and what they call the double-binding power of Swedish Whiteness. It means that 'the old Sweden', presented as a racially homogenous Swedish society, and 'the good Sweden', described as an anti-racist and feminist country, apparently irreconcilable, were both perceived, by a significant portion of the population, as under siege due to the influx of non-White and non-Western migrants. ${ }^{49}$ Major world and local events took place between 2011-2016 ranging from the migration crisis, natural disasters to terror attacks. However, this study does not have the objective of comparing the power and intensity of the events with previous historical periods. Presumedly yet, the impact of these occurrences on the general population and consequently nursing students was amplified by the media in terms of overload of information, instant notifications, multiplicity, and heterogeneity of the different mediatic outlets. ${ }^{51,52}$

During the 2011-2012 period, the search for the deeper meaning of globality in relation to nursing, with an emphasis on the RCRC principles, was under development at the SRCUC. ${ }^{31}$ This academic effort was partly motivated by the perceived rapid escalation in the number of events requiring humanitarian interventions, nationally and globally, which is closely related to both the nursing profession as well the RCRC perspective. ${ }^{53,54}$ This engagement is illustrated in the three themes 'Humanitarian aspects of advocacy and activism', 'Global fragility in the local context' and 'The global transition of activism and professional development'. Eurocentrism ${ }^{55}$ and White racial dominance ${ }^{56,57}$ have been recurrent concerns internationally in nursing education. McGibbon et al. claim that Eurocentric cultural beliefs are linked to classism, sexism, and racism and that they have an influence on social justice. ${ }^{58}$ Furthermore, hegemonism and post-colonialism through the actions of humanitarian organizations ${ }^{59}$ are closely related to Eurocentrism and relevant in this discourse. ${ }^{60}$ Indeed, the risk of a monolithic northern/Western universalizing hegemonic gaze cannot be totally ignored at the SRCUC pedagogical level, and it is also conceivable that SRCUC teachers through the years have promoted, unwillingly, a Eurocentric global perspective as an academic forum tends to be influenced by its cultural context and history. ${ }^{61}$ However, these three themes do not suggest any of these harmful aspects and, on the contrary, display a universality in their approach. Another finding, 'Advocating participation in caring relations', reflects directly the philosophical and theoretical aspect of nursing science from Northern Europe. ${ }^{62,63}$ Indeed, the Nordic tradition of caring science has had a substantial impact on healthcare research and education as well as clinical development in the Nordic region starting in the 1990s. It views caring science as a human science and caring as a natural phenomenon: '... where the patient's world, vulnerability, health, and suffering are primary. In the art and act of caring, relationships and dialogue are essential; they provide parameters where caring becomes visible in its absence'. ${ }^{63}$ This theoretical approach, in line with the SRCUC academic profile, reveals caring as a genuine act where the patient's experience is central. The theme 'Ecology of nursing in global health contexts' integrates the fundamental art of nursing to a global dimension. It shows that the students have understood one professional challenge that they are facing, which is to transform global ecosystem concern and ecological principles into a professional pursuit. $^{64}$ This finding assumes also that ecology has an ethical dimension in the context of nursing. An ecological model accepts that nurses are motivated by the intricate ethical and social systems in which moral actions are necessary. ${ }^{65}$ Clarifying a nursing ecological theory may steer the profession to new paths in holistic care and will be positive for the patients, profession, and the planet. ${ }^{64}$

The years 2015-2016 were marked particularly by the migration crisis in Sweden, ${ }^{66,67}$ which stimulated much 
discussion in the media. ${ }^{68-70}$ This humanitarian catastrophe exposed multiple global problems such as the role of democracy and globalization, ethical and geo-political issues, and social ecology. ${ }^{71,72}$ Consequently, the global workplace had developed into an emerging reality for health workers. ${ }^{73}$ The combination of the three themes 'Integrating sustainability and advocacy with holistic nursing', 'The meaning of ethical principles' and 'Challenges in nursing actions for a complex future' condenses well the overall content of the overarching theme representing this period. It shows how the students conceptualized the art of nursing and ethics in complex nursing actions. Simultaneously during this time, the developmental effort to clarify the SRCUC profile area was almost finalized. ${ }^{31}$ One can suspect that global events created a synergetic response through ostensibly influencing the academic and professional interests of the students in which ethical issues and interest in specialist nursing had become central. This combined effect increased the intricately complex interests of the students. Cruz et al. state that complexity in teaching recommends an emancipatory education built on social change and exploration. ${ }^{74}$

Finally, the theme 'Commitment to vulnerable populations with mental illnesses' reveals the growing interest during this period in global mental health issues by future nurses and the need to join actions filling the gaps still existing on prevention, treatment, quality of care and human rights protection. ${ }^{75}$ The original discussion of different views such as global and local perspectives on mental health has prompted more collaborative debate and complex interventions, and has joined other global policy platforms such as the SDGs. ${ }^{35,76}$ The SRCUC students, in this debate, had shown their capacity to be in tune with the global community regarding the issue of mental health.

\section{Methodological considerations}

The data collection and analysis were constructed according to different aspects related to trustworthiness to persuade the reader that the findings are worthy of attention. ${ }^{77,78}$ Keeping a self-critical account of the research process has been a central and constant concern. ${ }^{45}$ During the analysis and report writing, the use of reflexive journaling and written records were vital in developing the audit trail, and served as a reference for methodological decisions. ${ }^{45,46,79}$ One of the disadvantages with the thematic method is its flexibility, which might lead to inconsistency or a lack of coherence when developing themes. ${ }^{43}$ This was prevented by an assessment process mirrored through an examination of the reflexivity of the authors. ${ }^{77,80}$ To promote consistency and cohesion in the analysis, a close work with the framework as our epistemological position was applied. ${ }^{43}$ When defining the key findings, a coding matrix helped to extract the content from the large data set and to ensure credibility in the process. ${ }^{44}$ The matrix had to be outlined before commencing an in-depth analysis of the data. Consequently, the preparations before analysis were lengthened and this forced us to continue working towards the aims of the study in several steps. Hence, this technique was useful for this deductive, thematic analysis.

When readers can examine the research process, they are better able to judge the dependability of the research. ${ }^{45}$ This was ensured by applying the procedure of coding and creating the interpreted themes corresponding to the framework. Themes were derived from the indexed content in the texts and later changed in the light of the framework. King recommended that direct quotations are an essential component of the final report. ${ }^{44}$ Quotations were chosen to aid in the understanding of specific points of interpretation and to demonstrate the prevalence of the themes, also, to give readers a flavour of the source texts. ${ }^{44}$ Difficulties with finding proper quotations from the raw data occurred in themes that included more than 20 theses.

The key point of the concept of transferability refers to the extent to which findings can be applied to other settings. A sufficiently thick description of the phenomenon allows the reader to have a correct understanding of it and whether it can be applied to different contexts. ${ }^{45}$ The investigator's comparable concern for objectivity is the core of the concept of confirmability and may be defined by the reader as how far the data and concepts rising from it may be accepted. A complete methodological picture makes it available for the reader to define. ${ }^{45}$

\section{Conclusion}

The general outcome of this study reveals that SRCUC education has progressed towards a clearer global nursing vision between 2011 and 2016. Even though the findings demonstrate a positive academic development over time, they also point towards the importance of keeping the SRCUC profile continuously updated. Indeed, the combination of a global and RCRC humanitarian profile has a dynamic and fast-evolving dimension fuelled by ongoing global events and RCRC continuous interventions. It has an academic implication requiring a rapid and reactive teaching adaptation. More research is needed on the topic. One suggested area being a similar study describing how global nursing and global health, in conjunction with the RCRC perspective, are addressed and contextualized in the 2019-2021 bachelor's theses in respect to the hypothesized influence of COVID-19. Another study is to develop further the theoretical framework combining the three global entities defining the profile of the SRCUC.

\section{Acknowledgements}

We thank the students and our colleagues at the Swedish Red Cross University College who through the years have contributed to the academic development of the school.

\section{Conflict of interest}

The authors declare that there is no conflict of interest.

\section{Funding}

The authors disclosed receipt of the following financial support for the research, authorship, and/or publication of this article: This work was supported by the Swedish Red Cross University College.

\section{ORCID iDs}

Stéphanie Paillard Borg (D) https://orcid.org/0000-0002-1968-2326 Mia Kraft (D) https://orcid.org/0000-0001-5389-0746 


\section{Supplemental material}

Supplemental material for this article is available online.

\section{References}

1. International Council of Nurses (ICN). The ICN code of ethics for nurses. www.icn.ch/images/stories/documents/about/icncode_ english.pdf (2021, accessed 7 September 2021).

2. Drennan VM and Ross F. Global nurse shortages: the facts, the impact and action for change. Br Med Bull 2019; 130: 25-37.

3. Lavazza A and Farina M. The role of experts in the Covid-19 pandemic and the limits of their epistemic authority in democracy. Front Public Health 2020; 8: 356.

4. Jogerst K, Callender B, Adams V, et al. Identifying interprofessional global health competencies for 21 st-century health professionals. Ann Glob Health 2015; 81: 239-247.

5. Wilson L, Callender B, Hall TL, et al. Identifying global health competencies to prepare 21 st century global health professionals: report from the global health competency subcommittee of the consortium of universities for global health. J Law Med Eth 2014; 42: 26-31.

6. Wilson L, Mendes IA, Klopper H, et al. 'Global health' and 'global nursing': proposed definitions from the global advisory panel on the future of nursing. J Adv Nurs 2016; 72: 1529-1540.

7. Kraft M, Kästel A, Eriksson H, et al. Global nursing: a literature review in the field of education and practice. Nurs Open 2017; 4: 122-133.

8. Crigger NJ. Towards a viable and just global nursing ethics. Nurs Eth 2008; 15: 17-27.

9. Kulage KM, Hickey KT, Honig JC, et al. Establishing a program of global initiatives for nursing education. J Nurs Educ 2014; 53: 371-378.

10. Parcells $\mathrm{C}$ and Baernholdt $\mathrm{M}$. Developing a global curriculum in a school of nursing. J Nurs Educ 2014; 53: 692-695.

11. Riner M. Globally engaged nursing education: an academic program framework. Nurs Outlook 2011; 59: 308-317.

12. Seloilwe ES. Globalization and nursing. J Adv Nurs 2005; 50: 571-577.

13. Van Herk KA, Smith D and Andrew C. Examining our privileges and oppressions: incorporating an intersectionality paradigm into nursing. Nurs Inq 2011; 18: 29-39.

14. Grootjans $\mathrm{J}$ and Newman S. The relevance of globalization to nursing: a concept analysis. Int Nurs Rev 2013; 60: 78-85.

15. Bradbury-Jones C. Globalisation and its implications for health care and nursing practice. Nurs Stand 2009; 23: 43-47.

16. Chavez F, Bender A, Hardie K, et al. Becoming a global citizen through nursing education: lessons learned in developing evaluation tools. Int J Nurs Educ Scholarsh 2010; 7: 44.

17. Carlson E, Stenberg M, Chan B, et al. Nursing as universal and recognisable: nursing students' perceptions of learning outcomes from intercultural peer learning webinars: a qualitative study. Nurse Educ Today 2017; 57: 54-59.

18. Lenz BK and Warner S. Global learning experiences during a domestic community health clinical. Nurs Educ Perspec 2011; 32: 26-29.

19. Hovland OJ and Johannessen B. What characterizes Norwegian nursing students' reflective journals during clinical placement in an African country? Int J Afr Nurs Sci 2015; 4: 47-52.

20. De Natale ML and Waltz CL. Reflections of nursing students travel abroad experiences in Ireland: a global nursing perspective. Nurs Educ Perspec 2015; 36: 188-199.

21. Edmonds ML. The lived experience of nursing students who study abroad: a qualitative inquiry. J Stud Int Educ 2010; 14 : 545-568.
22. Harrowing JN, Gregory DM, O'Sullivan PS, et al. A critical analysis of undergraduate students' cultural immersion experiences. Int Nurs Rev 2012; 59: 494-501.

23. Kelleher S. Perceived benefits of study abroad programs for nursing students: an integrative review. J Nurs Educ 2013; 52: 690-695.

24. Kirkham S R, Van Hofwegen L and Pankratz D. Keeping the vision: sustaining social consciousness with nursing students following international learning experiences. Int J Nurs Edu Scholarsh 2009; 6: 3-9.

25. Ewertsson M, Bagga-Gupta S, Allvin R, et al. Tensions in learning professional identities: nursing students' narratives and participation in practical skills during their clinical practice: an ethnographic study. BMC Nurs 2017; 16: 48-53.

26. Ewertsson M, Bagga-Gupta S and Blomberg K. Nursing students' socialisation into practical skills. Nurs Educ Pract 2017; 27: 157164.

27. Holmgren J. Global nursing: educating future nurses for tomorrow's nursing care needs. Nord J Nurs Res 2017. Epub ahead of print 27 June 2017.

28. von Strauss E, Egmar A-C and Löfgren T. The Swedish Red Cross University College. J Hum Stud 2015; 4: 55-61.

29. Jønland Højsgaard T. Reframed identity: Red Cross nurses' identity formation between 1945 and 1977. PhD Thesis, Stockholm University, Sweden, 2019.

30. Koplan JP, Bond TC, Merson MH, et al. Towards a common definition of global health. Lancet 2009; 373: 1993-1995.

31. Holmgren $J$ and Kraft M. A global nursing framework in the Swedish Red Cross undergraduate nursing program. Nord J Nurs Res 2017. Epub ahead of print 27 November 2017.

32. Fried LP, Bentley ME, Buekens P, et al. Global health is public health. Lancet 2010; 375: 535-537.

33. Cernerud L, Arnesson H, Kugelberg S, et al. Folkhälsovetenskap arbetet med ämnets definition [Public health science: work on the definition of the subject]. Socialmed tidskr 2009; 86: 7-10.

34. The Swedish Red Cross University College. Global nursing and global health. https://www.rkh.se/en/about-us/swedish-red-crossuniversity-college (2021, accessed 24 March 2021).

35. United Nations. Transforming our world: the 2030 agenda for sustainable development. https://sustainabledevelopment.un.org/ post2015/transformingourworld (2015, accessed 2 April 2021).

36. Schiffling S, Hannibal C, Tickle M, et al. The implications of complexity for humanitarian logistics: a complex adaptive systems perspective. Ann Oper Res 2020; 29: 1-32.

37. International Federation of the Red Cross and Red Crescent Societies. The Future Red Cross and Red Crescent - Thematic Futures S2030 - First Milestone Trends Paper. chromeextension://efaidnbmnnnibpcajpcglclefindmkaj/viewer.html?pdfurl= https $\% 3 \mathrm{~A} \% 2 \mathrm{~F} \% 2$ Fsolferinoacademy.com $\% 2$ Fwp-content $\% 2$ Fuploads $\% 2 \mathrm{~F} 2018 \% 2 \mathrm{~F} 07 \% 2 \mathrm{FENStrategic-session-development-of-S2030.}$ pdf\&clen $=2176249 \&$ chunk $=$ true $(2018$, accessed 20 November 2020).

38. Evans D. Systematic reviews of interpretive research: interpretive data synthesis of processed data. Aust J Adv Nurs 2002; 20: 22-26.

39. Pope C, Ziebland S and Mays N. Qualitative research in health care: analyzing qualitative data. $\mathrm{Br}$ Med $J$ 2000; 8: 114-116.

40. O'Brien BC, Harris IB, Beckman TJ, et al. Standards for reporting qualitative research: a synthesis of recommendations. Acad Med 2014; 89: 1245-1251.

41. Rippon HR. The digital crusades: the media and Western European nationalists. PhD Thesis, Queensland University of Technology, Australia, 2016. 
42. Hodalska M. Stories of fear, horror, and terror: the price that the storytellers pay. In: Callaghan M and Davis K (eds) Cultural experiences of fear, horror, and terror. Oxford: Inter-Disciplinary Press, 2016, pp.147-156.

43. Braun V and Clarke V. Using thematic analysis in psychology. Qual Res Psychol 2006; 3: 77-101.

44. King N. Using templates in the thematic analysis of text. In: Cassell $\mathrm{C}$ and Symon $\mathrm{G}$ (eds) Essential guide to qualitative methods in organizational research. London: Sage, 2004, pp.257-270.

45. Lincoln YS and Guba EG. Naturalistic inquiry. London: Sage, 1985.

46. Sandelowski M. Qualitative analysis: what it is and how to begin. Res Nurs Health 1995; 18: 371-375.

47. The Ministry of Education and Cultural Affairs. The Act concerning the ethical review of research involving humans, Swedish Ethical Review Act. SFS number 2003.460 2003. https://www. onep.se/media/2348/the_ethical_review_act.pdf (2003, accessed 29 January 2021).

48. Rojek C. Event power: how global events manage and manipulate. London: Sage, 2013, pp.110-155.

49. Hübinette T and Lundström C. Sweden after the recent election: the double-binding power of Swedish Whiteness through the mourning of the loss of 'old Sweden' and the passing of 'good Sweden'. NORA—Nord J Fem and Gend Res 2011; 19: 42-52.

50. Hübinette $T$ and Lundström C. Swedish Whiteness and White melancholia. In: Watson V, Howard-Wagner D and Spanierman L (eds) Unveiling Whiteness in the twenty-first century: global manifestations, transdisciplinary interventions. London: Lexington Books, 2014, pp.49-74.

51. Houston JB, Spialek ML and First JM. Disaster media effects: a systematic review and synthesis based on the differential susceptibility to media effects model. $J$ Communic 2018; 68: 734-757.

52. Schmitt JB, Debbelt CA and Schneider FM. Too much information? Predictors of information overload in the context of online news exposure. Inf Comm \& Soc 2018; 21: 1151-1167.

53. Bloch A and Chimienti M. Irregular migration in a globalizing world. Ethnic Racial Stud 2011; 34: 1271-1285.

54. Castles S. Migration, crisis, and the global labor market. Globalizations 2011; 8: 311-324.

55. Hassouneh D. Anti-racist pedagogy: challenges faced by faculty of color in predominantly White schools of nursing. J Nurs Educ 2006; 45: 255-262.

56. Garland R and Batty ML. Moving beyond the rhetoric of social justice in nursing education: practical guidance for nurse educators committed to anti-racist pedagogical practice. Witness: Canadian J Crit Nurs Dis 2021; 30: 17-30.

57. Bell B. White dominance in nursing education: a target for antiracist efforts. Nurs Inq 2021; 28: e1-e11.

58. McGibbon E, Mulaudzi FM, Didham P, et al. Toward decolonizing nursing: the colonization of nursing and strategies for increasing the counternarrative. Nurs Inq 2015; 21: 179-191.

59. Rubinstein RA, Sanchez SN and Lane SD. Coercing consensus? Notes on power and the hegemony of collaboration. In: Gerard
$\mathrm{C}$ and Kriesberg L (eds) Conflict and collaboration, for better or worse. London: Routledge, 2018, pp.104-119.

60. Nayar KP. Postcolonialism: a guide for the perplexed. London: Bloomsbury, 2010.

61. Miles JM and Scott ES. A new leadership development model for nursing education. J Prof Nurs 2019; 35: 5-11.

62. Holopainen G, Nyström L and Kasén A. The caring encounter in nursing. Nurs Ethics 2019; 26: 7-16.

63. Rehnsfeldt A, Arman $M$ and Lindström UÅ. Clinical caring science as a scientific discipline. Scan J Car Sci 2017; 31: 641-646.

64. Laustsen G. Environment, ecosystems, and ecological behavior: a dialogue toward developing nursing ecological theory. Adv Nurs Sci 2006; 29: 43-54.

65. Copeland D. Moral ecology in nursing: a pluralistic approach. SAGE Open Nurs 2019; 5: 1-8.

66. Braithwaite A and Chu TS. Civil conflicts abroad, foreign fighters, and terrorism at home. J Confl Res 2018; 62: 1636-1360.

67. Gordy M. Disaster risk reduction and the global system: ruminations on a way forward. New York, NY: Springer, 2016, pp.55-99.

68. Eliassi B. Conceptions of immigrant integration and racism among social workers in Sweden. J Progr Hum Serv 2017; 28: 6-35.

69. Emilsson H. Continuity or change? The refugee crisis and the end of Swedish exceptionalism. Report, Malmö University, Malmö, Sweden, June 2018.

70. Kaneberg E, Hertz S and Jensen L. Emergency preparedness planning in developed countries: the Swedish case. J Hum Log Suppl Ch Man 2016; 6: 145-172.

71. Peters LER and Kelman I. Critiquing and joining intersections of disaster, conflict, and peace research. Int J Disaster Risk Sci 2020; 11: 555-567.

72. Miles EM, Narayan AJ and Watamura SE. Syrian caregivers in perimigration: a systematic review from an ecological systems perspective. Trans Iss Psych Sci 2019; 5: 78-90.

73. Okenwa-Emegwa L, Paillard-Borg S, Tinghög P, et al. A global workspace is the emerging reality for future public health workforce. Socialm Tidsk 2017; 94: 132-140.

74. Cruz RA, Araujo EL, Nascimento NM, et al. Reflections in the light of the complexity theory and nursing education. Rev Bras Enferm 2017; 70: 236-239.

75. Caldas-de-Almeida JM. Four reflections on the new global mental health priorities. Epidem Psych Sci 2020; 29: 1-4.

76. Bemme D and Kirmayer LJ. Global mental health: interdisciplinary challenges for a field in motion. Transcult Psych 2020; 57: 3-18.

77. Sandelowski M. Rigor or rigor mortis: the problem of rigor in qualitative research revisited. Adv Nurs Sci 1993; 16: 1-8.

78. Rolfe G. Validity, trustworthiness, and rigor: quality and the idea of qualitative research. $J$ Adv Nurs 2006; 53: 304-310.

79. Koch T. Establishing rigour in qualitative research: the decision trail. J Adv Nurs 1994; 19: 976-986.

80. Bott M. Favorites and others: reflexivity and the shaping of subjectivities and data in qualitative research. Qual Res 2010; 10 : 159-173. 